\title{
O IMPACTO NAS VARIAÇÕES DAS MATRIZES ENERGÉTICAS E USO DA TERRA: ESTUDO SOBRE A EFICIÊNCIA AMBIENTAL DO G20
}

\author{
Alexandre Pereira Salgado Junior* \\ asalgado@usp.br \\ Luciano Aparecido dos Santos Pimentel* \\ lpimentel@usp.br \\ Marcio Mattos Borges de Oliveira* \\ mmattos@usp.br \\ Juliana Chiaretti Novi* \\ juliananovi@fearp.usp.br \\ *Universidade de São Paulo
}

http://dx.doi.org/10.1590/1413.2311.013.62781

Recebido em 05/03/2016

Aprovado em 26/05/2017

Disponibilizado em 07/08/2017

Avaliado pelo sistema "doubleblindreview"

Revista Eletrônica de Administração

Editoras-chefe: Andrea Oltramari e Maria Ceci Misoczky

ISSN 1413-2311 (versão "online")

Editada pela Escola de Administração da Universidade Federal do Rio Grande do Sul

Periodicidade: Quadrimestral

Sistema requerido: Adobe Acrobat Reader

\section{RESUMO}

O objetivo foi avaliar o impacto na variação da matriz energética e da área das mudanças no uso da terra (reflorestamento, florestamento ou desmatamento) na redução de emissão de gases de efeito estufa entre os países membros do G20, no decênio 1990-2000-2010. A técnica de Análise Envoltória de Dadosfoi empregada no cálculo dos scorespara avaliar a eficiência relativa dos países do G20.Os resultados evidenciam que as alterações na matriz energética (maior consumo de fontes menos poluentes) influenciam no desempenho em relação aos demais países e que as mudanças no uso da terra são fatores preponderantes no desempenho do país, em relação a ele mesmo e aos outros, ao longo do tempo.

Palavras-chave: Eficiência. Energia. Uso da Terra. MeioAmbiente.

\begin{abstract}
The aim was to evaluate the impact on the variation of the energy matrix and the area of changes in land use (reforestation, afforestation and deforestation) in the reduction of greenhouse gases among the G20 member countries, in ten years 1990-2000-2010. The data envelopment analysis technique was used to calculate the scores to assess the relative efficiency of the G20 countries. The results show that changes in the energy matrix (higher
\end{abstract}


consumption of less polluting sources) influence the performance in relation to other countries and that changes in land use are important factors in the country's performance in relation to himself and to others, over time.

Key words: Efficiency. Energy. Land use. Environment.

\section{RESUMEN}

El objetivo fueevaluarel impacto de lavariación de la matriz energética y la zona de loscambiosenel uso delsuelo (reforestación, forestación y deforestación) enlareducción de gases de efectoinvernadero entre los países miembrosdel G-20, endiezaños 1990-2000-2010. La técnica de análisis envolvente de datos se utilizó para calcular lapuntuación para evaluarlaeficiencia relativa de los países del G-20. Los resultados muestran que loscambiosenla matriz energética (mayor consumo de lasfuentes menos contaminantes) influyenenelrendimientoenrelaciónconotros países, y que loscambiosenel uso delsuelosonfactores importantes eneldesempeñodel país enrelaciónconsímismo y conlosdemás, a lo largo deltiempo.

Palabras clave: Eficiencia. Energía. Uso delsuelo. Ambiente.

\section{INTRODUÇÃO}

As questões ambientais discutidas durante a realização de conferências globais além de estudos sobre o tema,baseiam-se na problemática envolvendo aemissão de gases de efeito estufa (GEE) e o aquecimento global. Este, considerado uma das importantes ameaças ambientais, sobretudo quando associadoa atividades antropogênicas, acarreta altos custos ambientais diante do uso dos recursos naturais necessários à produção e ao consumo energético (PORTIER et al., 2013).

Ante isso, oprocesso de industrialização figura-se como um dos mais impactantes e, ao longo dos anos, os países passaram a questionar seus modelos vigentes buscando estimular o crescimento e o desenvolvimento para mitigar esses prejuízoscausados ao meio ambiente (GOLDEMBERG; LUCON, 2008).

Em 1997, foi proposto pelo Protocolo de Kyoto que os países desenvolvidos deveriam ter uma meta de redução de emissão de GEE, pois foram os principais responsáveis pelas emissões e pelo alto padrão de consumo ao longo dos anos (McLEAN; STONE, 2014; HUBER, 2008).No entanto, isto poderia incorrer na redução de sua produção industrial e, consequentemente, redução na renda, no consumo e no crescimento econômico.

Por outro lado, os países em desenvolvimento deveriam adotar políticas preservacionistas que acarretam restrições aos fluxos demográficos e às atividades econômicas, além depoderem 
reivindicar compensações financeiras e transferência de tecnologia em troca de adoção de políticas de conservação e preservação do meio ambiente.

Dessa forma, o emprego de fontes de energia renováveis e menos poluentes poderá figurar entre as possíveis soluções para que os países continuem produzindo, mas com redução de impactos ambientais. Além disso, os efeitos do aquecimento global podem ser mitigados caso ocorra a reduçãoda concentração de GEE pelo aumento da área de floresta (por meio de florestamento e reflorestamento), de projetos ou de mecanismos de desenvolvimento limpo (MDL).

Portanto, estudos relacionados as alterações nas matrizes energéticas dos países e nas mudanças no uso da terra, podem contribuir com considerações ou propostas para um cenário mais sustentável. E, nesse sentido, o objetivo geral deste trabalho é avaliar o impacto na variação da matriz energética e da área das mudanças no uso da terra (reflorestamento, florestamento ou desmatamento) na redução de emissão de GEE entre os países membros do G20 nos anos 1990, 2000 e 2010.

\section{REFERÊNCIA BIBLIOGRÁFICA}

\subsection{Eficiência e Análise Envoltória de Dados (DEA)}

A distinção entre os conceitos de produtividade e eficiência é essencial, assim, a produtividade pode ser conceituada como a razão entre o que foi produzido (output) com o que foi gasto para produzir (input) (ÇELEN, 2013).

Diversas áreas do conhecimento utilizam estudos sobre eficiência buscando relacionar outputs (volume de bens e/ou serviços produzidos) e inputs (volume de recursos consumidos) (SALGADO JUNIOR; NOVI, 2015). A eficiência pode ser definida como a relação entre um indicador e seu correspondente máximo (ótimo), resultando em um valor entre 0 e 1 (AVKIRAN; PARKER, 2010). Na literatura, dentre as técnicas empregadas para se mensurar a eficiência está a Análise Envoltória de Dados, que é originada do inglês Data EnvelopmentAnalysis(DEA).

As técnicas não paramétricas buscam calcular a eficiência a partir da construção de uma fronteira de eficiência (BIAN; HE; XU, 2013), assim, a eficiência é relativa ao grupo estudado. Essa técnica permite que a eficiência seja orientada ao input ou ao output. O modelo adotado para este trabalho é o modelo proposto por Banker, Charnes e Cooper (BCC), 
orientado a output, com retornos variáveis de escala que representa a capacidade de aumentar a produção sem aumentar os insumos (inputs) (SALGADO JUNIOR et al., 2014).

Para Sarafidis (2002), a DEA utiliza técnicas de programação linear matemática a fim de encontrar o conjunto de pesos para cada unidade tomadora de decisão e que maximize o seu score de eficiência. Essas unidades tomadoras de decisão são frequentemente apresentadas na literatura como DecisionMakingUnits (DMUs). Desta forma, a DMU é comparada com sua projeção na fronteira eficiente, sendo que o valor da eficiência é limitado, entre 0 e 1 (em que a eficiência é máxima).

De acordo com Cooper, Seiford e Tone (2007), para a obtenção de resultados consistentes é importante que as DMUs sejam comparáveis (realizem as mesmas atividades e tenham objetivos semelhantes) e atuem nas mesmas condições; operem e utilizem múltiplos inputs e outputs (com diferenças apenas na intensidade de magnitude para cada DMU) e que o número de DMUs seja suficiente para validar o modelo.

\subsection{Mudanças no uso da terra}

Seiffert (2013) relata que, além das emissões de GEE, um fator que agravou o quadro das mudanças climáticas foi o processo de desmatamento, causado pelo uso da madeira como fonte de energia e matéria prima (desde antes da Revolução Industrial), pela expansão das cidades e pela expansão das atividades agropecuárias.

A redução (desmatamento) ou aumento (florestamento ou reflorestamento) na área de floresta de cada país, juntamente com as trocas com o meio (fotossíntese), implicam nas variações de estoque de carbono em cada país. Desta forma, a redução da área de floresta implica em redução do estoque de carbono e redução na capacidade de absorção de $\mathrm{CO}_{2}$ e o aumento da área de floresta, por sua vez, implica em maior absorção e consequente sequestro de carbono pelo meio ambiente. Neste sentido, a redução da área de floresta, além de reduzir a capacidade de absorção de $\mathrm{CO}_{2}$ pode promover liberação do carbono estocado para o meio ambiente por meio de queimadas.

A metodologia de absorção, sequestro e estoque de carbono, no entanto, não é consenso no meio acadêmico, em especial por envolver questões financeiras relacionadas aos créditos de carbono. Vários autores têm apresentado fórmulas e metodologias para seu cálculo, envolvendo conceitos de diversas áreas como biologia e estatística, além de especificidades de cada tipo de bioma. Dentre as propostas de cálculo da absorção, sequestro e variações no 
estoque de carbono estão metodologias sugeridas por diversos autores, além dos organismos internacionais IPCC e FAO.

O coeficiente de mudanças no uso da terra, proposto neste estudo, visa inserir no modelo o efeito do florestamento, reflorestamento e desmatamento e consequente acúmulo ou perda de carbono para o meio ambiente. O carbono é sequestrado e estocado no meio ambiente em florestas, por meio do crescimento da biomassa e das trocas gasosas com a atmosfera.

Vale destacar que o aumento da área de floresta indica que o país tem adotado medidas de florestamento ou reflorestamento, o que aumenta o potencial de sequestro de carbono. A absorção de dióxido de carbono pelo meio ambiente ocorre de diversas formas, sendo que no caso das florestas as formas de maior destaque são pela fotossíntese e pelo crescimento das florestas (em que o $\mathrm{CO}_{2}$ é absorvido e armazenado na árvore como um todo, da raiz às folhas) (GRID ARENDAL, 2013).

$\mathrm{O}$ Protocolo de Quioto estabeleceu metas para as emissões de GEE $\left(\mathrm{CO}_{2}, \mathrm{CH}_{4}, \mathrm{~N}_{2} \mathrm{O}\right.$, HFCs,PFCs, $\mathrm{SF}_{6}$ ), que podem ser satisfeitas através de esforços e atividades em todos os setores, incluindo energia, processos industriais, agricultura e gestão de resíduos. As atividades relacionadas ao uso da terra, mudança no uso da terra e florestas (LULUCF) também podem ser usadas de forma limitada para atingir as metas (HÖHNE et al., 2007).

\subsection{Fontes e matriz energética}

A determinação dos impactos do aquecimento global no século XXI é um tema controverso e coberto de incertezas (HINRICHS; KLEINBACH; REIS, 2012). O crescimento populacional e os padrões de consumo aumentam as preocupações em relação ao planeta, tendências e riscos (LEITE, 2013).

Segundo Seiffert (2013), a principal contribuição do ser humano para as mudanças climáticas está associada ao volume de emissões atmosféricas geradas nos processos produtivos.

A partir da década de 1940, o consumo energético cresceu em ritmo acelerado, refletindo a mudança profunda da civilização humana nos últimos 70 anos:aumento da população mundial, industrialização e difusão de eletrodomésticos e veículos particulares, concentração de população em centros urbanos e expansão de infraestrutura (GOLDEMBERG; LUCON, 2008). Para Ishiguro (2002), um fator que deve ser considerado na escolha da matriz energética é a competitividade econômica de cada fonte, especialmente nos investimentos para instalação e nos custos de geração de energia. 
Bronzatti e Iarozinski Neto (2008) consideram que outros fatores também são importantes para a decisão da composição da matriz energética como o potencial de produção e a probabilidade do crescimento de reservas.

O conceito da alteração da matriz energética é que os países deveriam buscar fontes de energia renováveis e menos poluentes, ajudando a mitigar os efeitos das mudanças climáticas e aquecimento global (SPADARO; LANGLOIS; HAMILTON, 2000). Neste sentido, devem ser consideradas para a tomada de decisão questões relativas às reservas energéticas e limitações de cada país, capacidade de aumentar a eficiência na geração de energia com a implementação de inovações tecnológicas e, também relevante, os custos tecnológicos e de produção de cada fonte energética (EIA, 2013).

Bronzatti e Iarozinski Neto (2008), baseados em dados da Turkenburg Utrecht University, fizeram um levantamento dos custos de geração de energia de cada fonte energética (combustíveis fósseis, energia nuclear e fontes renováveis) e identificaram que o petróleo é a fonte energética como menor custo de geração enquanto a eólica e solar apresenta os maiores custos. Os autores afirmam que o custo de geração de energia de US\$ 9,60 por megawatthora, o petróleo é a fonte energética menos onerosa, enquanto a energia solar, com US\$ 185,00 por megawatt-hora é a mais onerosa. Estas fontes, no entanto, apresentam apenas custos fixos de operações e manutenção, sem ter custos variáveis, o que dilui os custos em longo prazo (PINTO JUNIOR et al., 2007).

Sob o ponto de vista estritamente econômico, as fontes mais limpas (solar e eólica) deveriam ser descartadas, contudo são as que menos agridem o meio ambiente. Além de seu baixo custo relativo do petróleo, Hinrichs, Kleinbach e Reis (2012) destacam que o petróleo alimentou a maior parte do aumento do consumo desde a primeira metade do século $\mathrm{XX}$, devido também à sua adaptabilidade a diversos usos como aquecimento, transporte e produção de energia.

A eficiência energética pressupõe a implementação de estratégias e medidas para combater o desperdício de energia ao longo do processo de produção e aumentar a eficiência no seu uso.

Segundo Rosa, Fraceto e Moschini-Carlos (2012), energia é um recurso fundamental para o desenvolvimento dos países e é vista de maneira estratégica no cenário internacional. As fontes energéticas podem ser classificadas como renováveis (água, vento, sol e biomassa) e fontes não renováveis, o que inclui os combustíveis fósseis (carvão, petróleo e gás natural) além da energia nuclear (minérios radioativos como o urânio).

A combinação de avanços tecnológicos e da elevação do preço do barril de petróleo abriu um leque de alternativas para o desenvolvimento de oportunidade de petróleo e gás em áreas, 
inicialmente sem viabilidade econômica e geologicamente de difícil acesso (CORADESQUI; SANTOS, 2013).

Para Garman e Johnson (2013), uma das mais importantes mudanças no setor energético é relacionada ao pré-sal na América do Sul (em especial no Brasil) e ao gás de xisto (shalegas) e às jazidas de petróleo de xisto ou compacto (tightoil) na América do Norte.

Segundo a BP (2013), as principais reservas de carvão mineral estão localizadas na Ásia, América do Norte e em parte da Europa, sendo que as reservas do oriente médio, África e América Latina, juntos, correspondem a aproximadamente 5,3\% do total mundial.

Um levantamento feito pela Associação Brasileira de Energia Nuclear (ABEN, 2008), indica que o carvão, o petróleo e o gás natural são os principais emissores de GEE sendo que, dentre eles, o gás natural é considerado mais limpo. Os recursos renováveis (energia hidrelétrica, solar e eólica) são menos poluidores, juntamente com a energia nuclear.Segundo dados da AIEA (2012), 435 reatores nucleares estavam em operação e 65 reatores em construção, distribuídos pelos países.

\subsection{Países do G20}

“O G20 [...] é um fórum econômico, criado originalmente em 1999, que reunia os ministros das finanças e presidentes de bancos centraisde 19 países mais a União Europeia. A iniciativa da sua criação partiu dos Estados Unidos e do Canadá" (VIANA; CINTRA, 2010, p. 15). Os países selecionados são frequentemente segmentados em grupos: o grupo dos 8 (G8); o grupo dos 5 (G5) e os demais países do G20. O grupo formado pelo G8 é considerado o grupo de países mais ricos e industrializados (G7) além da Rússia. Este grupo foi, durante muito tempo, responsável pelas emissões de GEE no mundo, pela industrialização e pelo alto poder de consumo (RAMOS, 2014). Uma consideração importante sobre estes países é que eles receberam metas de redução de emissões, definidas pelo Protocolo de Quioto, fazendo com que buscassem meios para reduzir as emissões (HUBER, 2008).

O segundo grupo, o G5, é considerado como o grupo de países emergentes (CAMMACK, 2012). Segundo Kahler (2013), são países com industrialização um pouco mais recente, com taxa de crescimento relativamente alta e com grande população (juntos os 5 países representam mais de $40 \%$ da população mundial). Para Huber (2008) os países deste grupo não tiveram metas estabelecidas pelo Protocolo de Quioto que, juntamente com a industrialização recente e a grande população, têm contribuído para o aumento da participação nas emissões de GEE.

REAd - Porto Alegre - Edição 86 - No 2 - Maio / Agosto 2017 - p. 306 - 332 
Por fim, os demais países do G20 também são países emergentes, porém com crescimento inferior ao outro grupo de emergentes (G5). Representam este grupo (Outros Emergentes) os países Arábia Saudita, Argentina, Austrália, Coreia do Sul, Indonésia e Turquia. Além destes países (19 ao todo), a União Europeia também é considerada como membro do G20, mas não será analisada neste trabalho.

\section{PROCEDIMENTOS METODOLÓGICOS}

A pesquisa é explicativa, que utiliza como delineamento a pesquisa bibliográfica e desenvolvida a partir de livros e artigos nacionais e internacionais. Por comparar matrizes energéticas e variação de área de uso da terra, fez-se uso do método comparativo que procede pela investigação de indivíduos, classes, fenômenos ou fatos, com vistas a ressaltar as diferenças e similaridades entre eles e é indicado nas ciências sociais para comparar diferentes culturas, sistemas políticos, formas de governo ou países.

O tratamento especial foi relacionado ao cálculo do coeficiente de mudanças no uso da terra (que avalia considera absorção, sequestro e estoque de carbono para cada um dos países), levando em conta os estoques de carbono de cada tipo de bioma, as características geográficas de cada país e sua respectiva área de floresta. Para efetuar o cálculo, foram utilizados os dados propostos pelo IPCC, juntamente com os dados dos biomas de cada um dos países do G20 (DMUs do modelo) e as variações da área de floresta.

Os dados utilizados para a análise de eficiência foram retirados da BP Global e do World Bank. Foram selecionadas 20 DMUs, representando os países que compõem o grupo G20 e ainda é considerada a participação do Irã, pois ao longo do tempo tem aumentado sua participação nas emissões de GEE, sendo o $7^{\circ}$ país com maior emissão em 2010 e a $21^{\text {a }}$ maior economia em 2012.

As fontes das matrizes energéticas dos países são relacionadas com as emissões de GEE e com as variações de seu estoque de carbono. Assim, a Figura 1 ilustra as variáveis de input que são fontes energéticas (medidas em milhões de toneladas de óleo ou de óleo equivalente) e, de output que são as emissões de GEE (medidos em quilo toneladas de $\mathrm{CO}_{2}$ ou $\mathrm{CO}_{2}$ equivalente), com dedução da absorção de $\mathrm{CO}_{2}$ pelas florestas (coeficiente de mudança no uso da terra $-C_{m u t}$ ) por cada um dos países. 


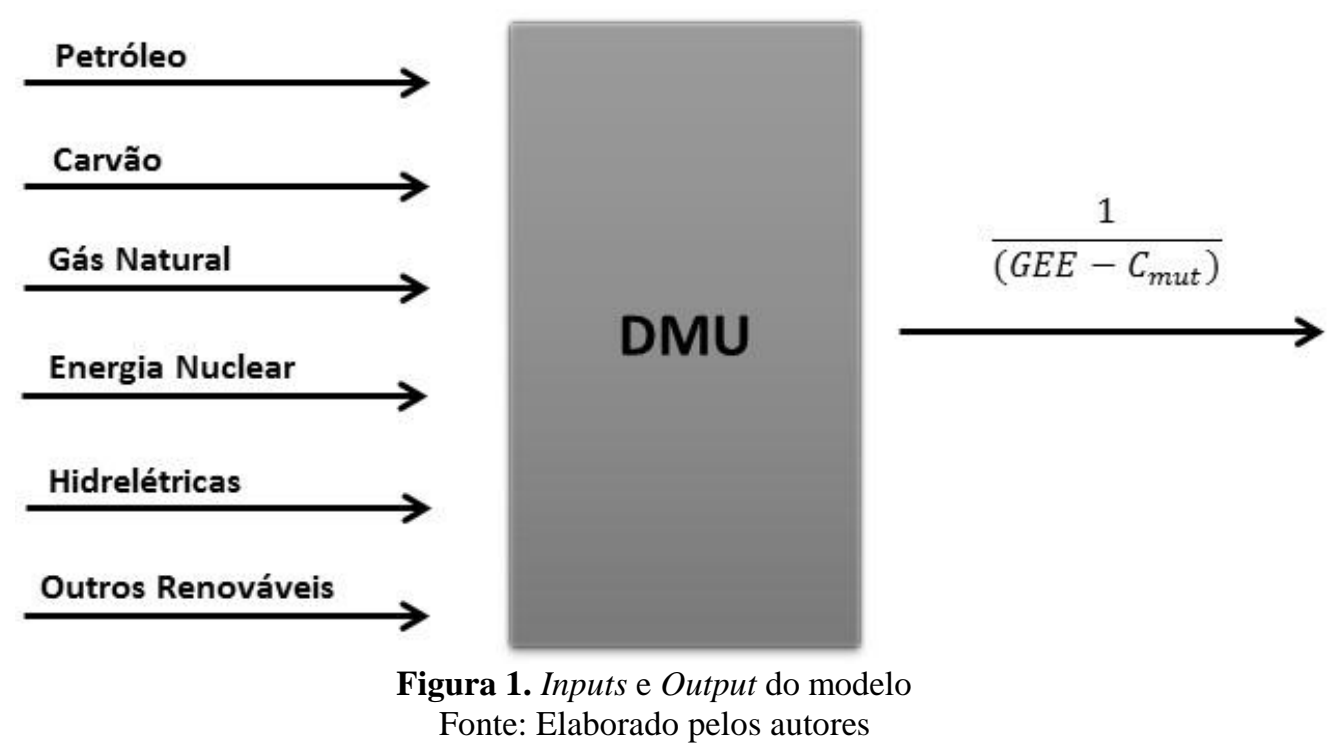

Para a construção do modelo, os GEE (dióxido de carbono, metano, óxido nitroso e outros gases) foram agrupados em um único output. Assim, para a análise de eficiência este modelo avalia qual combinação de fontes energéticas (matriz energética de cada país) produz uma menor quantidade de GEE.

A DEA permite que seja obtida uma eficiência relativa ao grupo estudado, pois as DMUs localizadas na fronteira são consideradas eficientes e as que estiverem localizadas abaixo são consideradas ineficientes.

Ainda que os valores de absorção, sequestro e estoque de carbono pareçam pouco significativos em relação ao total de GEE liberados no meio ambiente, a técnica DEA capta estas variações mais sensíveis e incorpora ao modelo a influência da área de floresta e variações no estoque de carbono nas florestas.

Por fim, a metodologia de análise de eficiência produtiva envolveu seis etapas: seleção das DMUs, seleção de inputs e outputs, escolha da técnica (DEA), modelo e perspectiva, escolha da ferramenta computacional (software FrontierAnalyst), implementação técnica e análise dos resultados.

\section{DISCUSSÃO E ANÁLISE DOS RESULTADOS}

Pela análise de desempenho da técnica DEA foram feitas duas medições: análise temporal, considerando as vinte nações em cada período isolado; e análise por dados em painel, considerando o desempenho de todas as nações, em todos os períodos. Para efeito de análise foram feitas duas medições de desempenho, uma delas (análise temporal) considerando as 
vinte nações em cada período isolado e outra (análise por dados em painel) considerando o desempenho de todas as nações, em todos os períodos.

A análise temporal permite que sejam avaliados os países com melhor desempenho naquele específico ano. Ao desenvolver as três análises é possível verificar qual foi o desempenho relativo de cada uma das nações em determinado ano e comparar com o desempenho relativo nos outros anos. Com isso, é possível observar quais países (DMUs) melhoraram seu desempenho relativo e tornaram-se mais ou menos eficientes.

A análise por dados em painel, por sua vez, permite que seja avaliado o desempenho de cada país em relação a ele mesmo, utilizando como referência o ano base de 1990. Assim é possível analisar se as alterações na matriz energética e área de floresta permitiu melhoria de desempenho do país em relação às emissões de 1990.

Dos países analisados, dez apresentaram melhora ou tendência de melhora no desempenho relativo segundo a análise temporal, sendo que destes países apenas quatro (Alemanha, Itália, Reino Unido e Rússia) apresentaram melhora de desempenho em relação ao próprio desempenho de 1990 (análise por dados em painel). Dentre os países do G20, cinco países permaneceram relativamente eficientes em cada um dos anos analisados, contudo todos perderam eficiência em relação ao ano base. Por fim, cinco países (Brasil, China, Coreia do Sul, Índia e Indonésia) apresentaram redução de desempenho tanto na análise temporal quanto na análise por dados em painel.

Para auxiliar a compreensão das análises, a Tabela 1 apresenta o crescimento econômico dos países nos decênios 1991-2000 e 2001-2010, ondepodem ser comparados o crescimento do consumo energético e o crescimento econômico médio do país no período.

Tabela 1. Crescimento econômico médio nos decênios 1991-2000 e 2001-2010

\begin{tabular}{lcc}
\hline \multicolumn{1}{c}{ País } & $\begin{array}{c}\text { Cresc. Econômico Médio } \\
\mathbf{1 9 9 1 - 2 0 0 0}\end{array}$ & $\begin{array}{c}\text { Cresc. Econômico Médio } \\
\mathbf{2 0 0 1 - 2 0 1 0}\end{array}$ \\
\hline África do Sul & $1,8 \%$ & $3,6 \%$ \\
Alemanha & $1,9 \%$ & $1,0 \%$ \\
Arábia Saudita & $2,8 \%$ & $5,4 \%$ \\
Argentina & $4,7 \%$ & $3,4 \%$ \\
Austrália & $3,3 \%$ & $3,1 \%$ \\
Brasil & $2,6 \%$ & $3,6 \%$ \\
Canadá & $2,9 \%$ & $1,9 \%$ \\
China & $10,5 \%$ & $10,5 \%$ \\
Coreia do Sul & $6,2 \%$ & $4,2 \%$ \\
Estados Unidos & $3,5 \%$ & $1,7 \%$ \\
França & $2,0 \%$ & $1,1 \%$
\end{tabular}




\begin{tabular}{lll} 
Índia & $5,6 \%$ & $7,6 \%$ \\
Indonésia & $4,4 \%$ & $5,2 \%$ \\
Irã & $3,8 \%$ & $5,1 \%$ \\
Itália & $1,6 \%$ & $0,4 \%$ \\
Japão & $1,1 \%$ & $0,8 \%$ \\
México & $3,6 \%$ & $1,8 \%$ \\
Reino Unido & $3,1 \%$ & $1,7 \%$ \\
Rússia & $-3,6 \%$ & $4,9 \%$ \\
Turquia & $3,7 \%$ & $4,0 \%$ \\
\hline
\end{tabular}

Fonte: World Bank (2013)

Pode-se observar que em alguns países (DMUs) o crescimento econômico anual médio é alto em todo período, como é o caso da China, implicando em aumento do consumo energético e consequente aumento das emissões de gases de efeito estufa. Em outros casos, como a Rússia, no decênio 1991-2000 o crescimento foi negativo, resultado da reestruturação do país com o fim da União Soviética e das crises no fim da década. Outra importante consideração é que no decênio 2001-201 houve a crise imobiliária nos Estados Unidos e a crise econômica de 2008, causando redução no crescimento médio de alguns países.

$\mathrm{Na}$ análise temporal os países são comparados isoladamente a cada ano. Destaca-se que a eficiência, como já mencionado, é relativa. Assim, com base nos dados foi feita uma segmentação dos países para análise: (1) países sempre eficientes; (2) países que se tornaram eficientes; (3) países sempre ineficientes, com melhoria na eficiência relativa; (4) países sempre ineficientes com tendência de melhoria na eficiência relativa; (5) países que se tornaram ineficientes e (6) países sempre ineficientes com tendência de queda na eficiência relativa.

Os dados da análise de eficiência temporal podem ser observados na Tabela 2.

Tabela 2. Resultado da análise de eficiência temporal pelo modelo BCC (DEA)

\begin{tabular}{|c|c|c|c|}
\hline Países & 1990 & 2000 & 2010 \\
\hline África do Sul & $100,0 \%$ & $100,0 \%$ & $100,0 \%$ \\
\hline Alemanha & $5,8 \%$ & $12,2 \%$ & $23,1 \%$ \\
\hline Arábia Saudita & $100,0 \%$ & $100,0 \%$ & $100,0 \%$ \\
\hline Argentina & $100,0 \%$ & $100,0 \%$ & $100,0 \%$ \\
\hline Austrália & $55,8 \%$ & $84,5 \%$ & $100,0 \%$ \\
\hline Brasil & $100,0 \%$ & $99,9 \%$ & $57,3 \%$ \\
\hline Canadá & $21,8 \%$ & $20,8 \%$ & $32,0 \%$ \\
\hline China & $11,2 \%$ & $2,6 \%$ & $0,5 \%$ \\
\hline Coreia do Sul & $100,0 \%$ & $100,0 \%$ & $54,5 \%$ \\
\hline Estados Unidos & $0,2 \%$ & $0,2 \%$ & $0,4 \%$ \\
\hline França & $17,1 \%$ & $36,1 \%$ & $51,3 \%$ \\
\hline
\end{tabular}




\begin{tabular}{lccc} 
Índia & $11,0 \%$ & $6,3 \%$ & $5,0 \%$ \\
Indonésia & $100,0 \%$ & $88,9 \%$ & $74,3 \%$ \\
Irã & $100,0 \%$ & $81,0 \%$ & $100,0 \%$ \\
Itália & $43,7 \%$ & $60,6 \%$ & $99,5 \%$ \\
Japão & $3,5 \%$ & $6,3 \%$ & $7,8 \%$ \\
México & $47,1 \%$ & $47,2 \%$ & $47,5 \%$ \\
Reino Unido & $16,9 \%$ & $35,8 \%$ & $83,7 \%$ \\
Rússia & $1,9 \%$ & $14,2 \%$ & $17,0 \%$ \\
Turquia & $100,0 \%$ & $100,0 \%$ & $100,0 \%$ \\
\hline
\end{tabular}

Fonte: Elaborado pelos autores

No primeiro grupo, países sempre eficientes correspondem aos países com score igual a 100\% em todos os períodos analisados e correspondem aos países África do Sul, Arábia Saudita, Argentina e Turquia. O segundo grupo, Austrália e Irã, corresponde aos países que se tornaram eficientes em 2010, ou seja, que tinham score inferior a 100\% nos anos de 1990 e 2000 e atingiram o desempenho relativo máximo em 2010.

O terceiro grupo, importante para a análise, corresponde aos países que melhoraram sua eficiência relativa, com a maior variação entre o score inicial em 1990 e o final de 2010. Os países que representam este grupo são a Alemanha, França, Itália, Reino Unido e Rússia. Dentre os países deste grupo, apenas a França não melhorou seu desempenho relativo ao ano base (1990), sendo que os demais além de apresentarem melhora na análise temporal, também apresentaram evolução no desempenho na análise por dados em painel.

O quarto grupo corresponde aos países que apresentam tendência de melhoria no desempenho, ainda que de maneira mais discreta. São países que apresentaram melhora no desempenho da análise temporal, mas que pioraram seu desempenho relativo na análise por dados em painel, indicando que no ano base tinham eficiência relativa superior aos demais anos.

Os dois últimos grupos são formados por países que pioraram seu desempenho, sendo que o quinto grupo relaciona os países que foram considerados eficientes em 1990, mas que nos anos posteriores tiveram queda de desempenho (representado pelo Brasil, Coreia do Sul e Indonésia) e o sexto grupo são os países que sempre foram ineficientes e que ao longo do tempo pioraram seu desempenho.

Os dados em painel são utilizados para analisar o desempenho relativo dos países (com eles mesmos) ao longo do tempo. A grande maioria dos países teve queda no desempenho, sendo que apenas Alemanha, Itália, Reino Unido e Rússia, melhoraram seu desempenho indicando conseguiram ser relativamente mais eficientes em 2010 do que eram em 1990. Com isso, estes 
países seguem em direção aos objetivos lançados pelas Nações Unidas de que os países deveriam reduzir suas emissões em relação aos níveis de 1990. Os dados da análise com dados em painel são apresentados na Tabela 3.

Tabela 3. Resultado da análise de eficiência com dados em painel pelo modelo BCC

\begin{tabular}{|c|c|c|c|}
\hline Países & 1990 & 2000 & 2010 \\
\hline África do Sul & $100,0 \%$ & $76,1 \%$ & $65,9 \%$ \\
\hline Alemanha & $5,8 \%$ & $6,9 \%$ & $8,6 \%$ \\
\hline Arábia Saudita & $100,0 \%$ & $73,8 \%$ & $49,6 \%$ \\
\hline Argentina & $100,0 \%$ & $100,0 \%$ & $73,5 \%$ \\
\hline Austrália & $55,8 \%$ & $47,0 \%$ & $45,1 \%$ \\
\hline Brasil & $100,0 \%$ & $39,6 \%$ & $15,9 \%$ \\
\hline Canadá & $21,8 \%$ & $13,4 \%$ & $11,7 \%$ \\
\hline China & $11,2 \%$ & $0,6 \%$ & $0,1 \%$ \\
\hline Coreia do Sul & $100,0 \%$ & $39,4 \%$ & $18,7 \%$ \\
\hline Estados Unidos & $0,2 \%$ & $0,1 \%$ & $0,1 \%$ \\
\hline França & $17,1 \%$ & $17,4 \%$ & $16,6 \%$ \\
\hline Índia & $11,0 \%$ & $2,6 \%$ & $1,4 \%$ \\
\hline Indonésia & $100,0 \%$ & $53,10 \%$ & $34,5 \%$ \\
\hline Irã & $100,0 \%$ & $53,6 \%$ & $38,9 \%$ \\
\hline Itália & $43,7 \%$ & $42,3 \%$ & $47,0 \%$ \\
\hline Japão & $3,5 \%$ & $2,6 \%$ & $2,7 \%$ \\
\hline México & $47,1 \%$ & $23,9 \%$ & $17,2 \%$ \\
\hline Reino Unido & $16,9 \%$ & $20,8 \%$ & $26,6 \%$ \\
\hline Rússia & $1,9 \%$ & $5,8 \%$ & $2,5 \%$ \\
\hline Turquia & $100,0 \%$ & $71,4 \%$ & $56,9 \%$ \\
\hline
\end{tabular}

Fonte: Elaborado pelos autores

Ao observar a variação dos scores dos países entre 1990 e 2010, percebe-se que os países com maior variação positiva foram Reino Unido, Alemanha, Rússia, Itália e França enquanto os países com maior variação negativa (queda de eficiência) foram China, Índia, Brasil, Coreia do Sul e Indonésia.

Os dados também apontam que a maior concentração de países eficientes ocorre em 1990, sugerindo que houve queda no desempenho dos países ao longo do tempo, corroborando a proposta da ONU (Protocolo de Quioto) em reduzir as emissões aos níveis de 1990.

A seguir são detalhados os grupos de países que sempre foram eficientes, tornaram-se eficientes, melhoraram o desempenho relativo, pioraram seu desempenho relativo e tornaramse ineficientes.

\subsection{Comparação do desempenho das DMUs em função do $C_{m u t}$}


A metodologia adotada para este trabalho prevê um modelo com vários inputs e um único output, que considera tanto as emissões de gases de efeito estufa, quanto a absorção em cada tipo de bioma dos países (medida através do coeficiente de mudança no uso da terra - Cmut). Os resultados da Análise Temporal e da Análise com dados em Painel, quando comparados os modelos, percebe-se que os principais resultados não se alteram.

Estes corroboram a teoria ao apontar que, ainda que pouco representativa, as florestas podem promover alterações na eficiência e no desempenho dos países.

As principais alterações são em relação aos scores de eficiência de alguns países que, em função do uso da terra, apresentam melhor ou pior desempenho.

$\mathrm{Na}$ análise temporal foi possível observar que alguns países perderam eficiência quando não são consideradas as florestas, como é o caso do Brasil e Indonésia (países com grande cobertura de floresta tropical).

O mesmo ocorre com a Rússia e o Canadá, detentores de grandes áreas de floresta. A Tabela 4 sintetiza os dados da comparação entre os modelos.

Tabela 4. Análise Temporal (desempenho das DMUs sem considerar mudanças no uso da terra)

\begin{tabular}{lcccccc}
\hline \multirow{1}{*}{ Países } & \multicolumn{2}{c}{ Considerando $\mathbf{C}_{\text {mut }}$ no Output } & \multicolumn{3}{c}{ Sem considerar $\mathbf{C}_{\text {mut }}$ no Output } \\
& $\mathbf{1 9 9 0}$ & $\mathbf{2 0 0 0}$ & $\mathbf{2 0 1 0}$ & $\mathbf{1 9 9 0}$ & $\mathbf{2 0 0 0}$ & $\mathbf{2 0 1 0}$ \\
\hline África do Sul & $100,0 \%$ & $100,0 \%$ & $100,0 \%$ & $100,0 \%$ & $100,0 \%$ & $100,0 \%$ \\
Alemanha & $5,8 \%$ & $12,2 \%$ & $23,1 \%$ & $6,1 \%$ & $12,4 \%$ & $23,6 \%$ \\
Arábia Saudita & $100,0 \%$ & $100,0 \%$ & $100,0 \%$ & $100,0 \%$ & $100,0 \%$ & $100,0 \%$ \\
Argentina & $100,0 \%$ & $100,0 \%$ & $100,0 \%$ & $100,0 \%$ & $100,0 \%$ & $100,0 \%$ \\
Austrália & $55,8 \%$ & $84,5 \%$ & $100,0 \%$ & $50,6 \%$ & $77,0 \%$ & $100,0 \%$ \\
Brasil & $100,0 \%$ & $99,9 \%$ & $57,3 \%$ & $49,9 \%$ & $60,9 \%$ & $41,8 \%$ \\
Canadá & $21,8 \%$ & $20,8 \%$ & $32,0 \%$ & $10,7 \%$ & $12,0 \%$ & $18,7 \%$ \\
China & $11,2 \%$ & $2,6 \%$ & $0,5 \%$ & $11,0 \%$ & $2,6 \%$ & $0,6 \%$ \\
Coreia do Sul & $100,0 \%$ & $100,0 \%$ & $54,5 \%$ & $100,0 \%$ & $100,0 \%$ & $54,8 \%$ \\
Estados Unidos & $0,2 \%$ & $0,2 \%$ & $0,4 \%$ & $0,2 \%$ & $0,2 \%$ & $0,4 \%$ \\
França & $17,1 \%$ & $36,1 \%$ & $51,3 \%$ & $17,7 \%$ & $37,2 \%$ & $53,0 \%$ \\
Índia & $11,0 \%$ & $6,3 \%$ & $5,0 \%$ & $10,9 \%$ & $6,3 \%$ & $5,2 \%$ \\
Indonésia & $100,0 \%$ & $88,9 \%$ & $74,3 \%$ & $85,3 \%$ & $76,4 \%$ & $70,8 \%$ \\
Irã & $100,0 \%$ & $81,0 \%$ & $100,0 \%$ & $100,0 \%$ & $80,7 \%$ & $100,0 \%$ \\
Itália & $43,7 \%$ & $60,6 \%$ & $99,5 \%$ & $44,4 \%$ & $60,7 \%$ & $99,4 \%$ \\
Japão & $3,5 \%$ & $6,3 \%$ & $7,8 \%$ & $3,6 \%$ & $6,4 \%$ & $8,0 \%$ \\
México & $47,1 \%$ & $47,2 \%$ & $47,5 \%$ & $43,3 \%$ & $45,2 \%$ & $46,0 \%$ \\
Reino Unido & $16,9 \%$ & $35,8 \%$ & $83,7 \%$ & $17,2 \%$ & $36,1 \%$ & $84,5 \%$ \\
Rússia & $1,9 \%$ & $14,2 \%$ & $17,0 \%$ & $1,4 \%$ & $8,7 \%$ & $10,7 \%$ \\
Turquia & $100,0 \%$ & $100,0 \%$ & $100,0 \%$ & $100,0 \%$ & $100,0 \%$ & $100,0 \%$ \\
\hline & & Fonte: Elaborado pelos autores & & &
\end{tabular}


$\mathrm{Na}$ análise com dados em painel, o mesmo padrão se repete. Ao desconsiderar o uso de florestas no modelo o desempenho de alguns países cai, como é o caso do Brasil e Indonésia, Rússia e Canadá. Da mesma forma que ocorreu na análise temporal, o padrão dos países continua o mesmo, com alterações nos scores de eficiência. A Tabela 5 sintetiza os dados da comparação entre os modelos no desempenho dos países com dados em painel.

Tabela 5.1 Análise com dados em Painel (desempenho das DMUs sem considerar o Cmut)

\begin{tabular}{lrrrrrr}
\hline & Considerando $\mathbf{C}_{\text {mut }}$ no & Output & \multicolumn{3}{c}{ Sem considerar $\mathbf{C}_{\text {mut }}$ no Output } \\
Países & $\mathbf{1 9 9 0}$ & $\mathbf{2 0 0 0}$ & $\mathbf{2 0 1 0}$ & $\mathbf{1 9 9 0}$ & $\mathbf{2 0 0 0}$ & $\mathbf{2 0 1 0}$ \\
\hline África do Sul & $100,0 \%$ & $76,1 \%$ & $65,9 \%$ & $100,0 \%$ & $76,2 \%$ & $65,9 \%$ \\
Alemanha & $5,8 \%$ & $6,9 \%$ & $8,6 \%$ & $6,1 \%$ & $7,2 \%$ & $9,0 \%$ \\
Arábia Saudita & $100,0 \%$ & $73,8 \%$ & $49,6 \%$ & $100,0 \%$ & $73,9 \%$ & $49,6 \%$ \\
Argentina & $100,0 \%$ & $100,0 \%$ & $73,5 \%$ & $100,0 \%$ & $100,0 \%$ & $75,0 \%$ \\
Austrália & $55,8 \%$ & $47,0 \%$ & $45,1 \%$ & $50,6 \%$ & $43,0 \%$ & $41,6 \%$ \\
Brasil & $100,0 \%$ & $39,6 \%$ & $15,9 \%$ & $49,9 \%$ & $24,8 \%$ & $11,7 \%$ \\
Canadá & $21,8 \%$ & $13,4 \%$ & $11,7 \%$ & $10,7 \%$ & $7,9 \%$ & $7,0 \%$ \\
China & $11,2 \%$ & $0,6 \%$ & $0,1 \%$ & $11,0 \%$ & $0,6 \%$ & $0,1 \%$ \\
Coreia do Sul & $100,0 \%$ & $39,4 \%$ & $18,7 \%$ & $100,0 \%$ & $39,4 \%$ & $18,7 \%$ \\
Estados Unidos & $0,2 \%$ & $0,1 \%$ & $0,1 \%$ & $0,2 \%$ & $0,1 \%$ & $0,1 \%$ \\
França & $17,1 \%$ & $17,4 \%$ & $16,6 \%$ & $17,7 \%$ & $18,2 \%$ & $17,5 \%$ \\
Índia & $11,0 \%$ & $2,6 \%$ & $1,4 \%$ & $10,9 \%$ & $2,7 \%$ & $1,4 \%$ \\
Indonésia & $100,0 \%$ & $53,1 \%$ & $34,5 \%$ & $85,3 \%$ & $45,8 \%$ & $31,7 \%$ \\
Irã & $100,0 \%$ & $53,6 \%$ & $38,9 \%$ & $100,0 \%$ & $53,4 \%$ & $38,9 \%$ \\
Itália & $43,7 \%$ & $42,3 \%$ & $47,0 \%$ & $44,4 \%$ & $42,8 \%$ & $47,6 \%$ \\
Japão & $3,5 \%$ & $2,6 \%$ & $2,7 \%$ & $3,6 \%$ & $2,7 \%$ & $2,8 \%$ \\
México & $47,1 \%$ & $23,9 \%$ & $17,2 \%$ & $43,3 \%$ & $23,0 \%$ & $17,3 \%$ \\
Reino Unido & $16,9 \%$ & $20,8 \%$ & $26,6 \%$ & $17,2 \%$ & $21,3 \%$ & $27,0 \%$ \\
Rússia & $1,9 \%$ & $5,8 \%$ & $2,5 \%$ & $1,4 \%$ & $3,5 \%$ & $1,6 \%$ \\
Turquia & $100,0 \%$ & $71,4 \%$ & $56,9 \%$ & $100,0 \%$ & $71,9 \%$ & $57,4 \%$ \\
\hline & & Fonte: Elaborado pelos autores & & &
\end{tabular}

Fonte: Elaborado pelos autores

Com base nos dados analisados e discutidos e, na segmentação realizada neste estudo,dentre a categoria um (1), que são os países sempre eficientes, quatro apresentaram score de eficiência de 100\% nos três períodos analisados. São eles: a África do Sul, a Arábia Saudita, a Argentina e a Turquia. No grupo dois (2), que são os países que se tornaram eficientes em relação à emissão de GEE, foram identificados a Austrália e o Irã.

Dentre os países que nunca foram considerados eficientes (score de eficiência <100\%), alguns países apresentaram aumento significativo em suas avaliações de desempenho. Essa variação no aumento dos scores fez com que estes países fossem agrupados em países ineficientes com melhoria na eficiência relativa, que foi segmentado no grupo três (3), que são os países 
sempre ineficientes, com melhoria na eficiência relativa. São eles: Alemanha, Itália, Reino Unido e Rússia.

No grupo quatro (4), que são os países sempre ineficientes com tendência de melhoria na eficiência relativa, diferentemente do grupo anterior, apresentaram variações mais discretas entre os scores de eficiência e, por isso, são considerados países com tendência de melhoria de desempenho. Os países deste grupo são a França, Canadá, Estados Unidos, Japão e México.

O grupo cinco (5), que são os países que se tornaram ineficientes, ou seja, são países que, no ano de 1990, tinham score de eficiência de $100 \%$, mas que foram reduzindo seu desempenho ao longo do tempo estão o Brasil, a Coreia do Sul e a Indonésia.

No último grupo, (6) países sempre ineficientes com tendência de queda na eficiência relativa, dois países que sempre foram ineficientes pioraram seu desempenho, tanto na análise temporal quanto na análise com dados em painel. Os países que fazem parte deste grupo são a China e a Índia.

\subsection{Síntese da análise de eficiência}

A síntese da análise de eficiência envolve: a análise do quadro de matriz energética (Quadro 1), quadro resumo do consumo, absorção, emissões, a análise envoltória (Quadro 2), quadro resumo da eficiência dos países (Quadro 3) e scores dos países.

\subsubsection{Quadro matriz energética}

O Quadro 1 apresenta o resumo da matriz energética onde estão os países que melhoraram $(\boldsymbol{\Delta})$, pioraram $(\boldsymbol{\nabla})$ ou mantiveram constante $(-)$ seu consumo das fontes energéticas em relação à própria matriz energética e em relação aos demais países do G20. 
Quadro 1.Resumo do desempenho das matrizes energéticas

\begin{tabular}{|c|c|c|c|c|c|c|c|c|c|c|c|c|}
\hline \multirow{2}{*}{ País } & \multicolumn{2}{|c|}{ Petróleo } & \multicolumn{2}{|c|}{ Gás } & \multicolumn{2}{|c|}{ Carvão } & \multicolumn{2}{|c|}{ Nuclear } & \multicolumn{2}{|c|}{ Hidrelétrica } & \multicolumn{2}{|c|}{ Renováveis } \\
\hline & Matriz & G20 & Matriz & G20 & Matriz & G20 & Matriz & G20 & Matriz & G20 & Matriz & G20 \\
\hline $\begin{array}{l}\text { Africa do } \\
\text { Sul }\end{array}$ & $\nabla$ & $\nabla$ & $\Delta$ & $\boldsymbol{\Delta}$ & $\boldsymbol{\Delta}$ & $\Delta$ & $\Delta$ & $\Delta$ & $\nabla$ & $\nabla$ & $\boldsymbol{\Delta}$ & $\Delta$ \\
\hline Alemanha & $\Delta$ & $\Delta$ & $\Delta$ & $\nabla$ & $\Delta$ & $\Delta$ & $\nabla$ & $\nabla$ & $\Delta$ & $\nabla$ & $\Delta$ & $\Delta$ \\
\hline $\begin{array}{l}\text { Arábia } \\
\text { Saudita }\end{array}$ & $\boldsymbol{\Delta}$ & $\nabla$ & $\boldsymbol{\Lambda}$ & $\Delta$ & - & - & - & - & - & - & - & - \\
\hline Argentina & $\Delta$ & $\nabla$ & $\Delta$ & $\boldsymbol{\Delta}$ & $\Delta$ & $\boldsymbol{\Delta}$ & $\nabla$ & $\nabla$ & $\Delta$ & $\Delta$ & $\boldsymbol{\Delta}$ & $\boldsymbol{\Delta}$ \\
\hline Austrália & $\boldsymbol{\Delta}$ & $\nabla$ & $\boldsymbol{\Delta}$ & $\nabla$ & $\nabla$ & $\boldsymbol{\Delta}$ & - & - & $\nabla$ & $\nabla$ & $\boldsymbol{\Delta}$ & $\Delta$ \\
\hline Brasil & $\Delta$ & $\nabla$ & $\Delta$ & $\Delta$ & $\Delta$ & $\Delta$ & $\Delta$ & $\Delta$ & $\nabla$ & $\Delta$ & $\Delta$ & $\Delta$ \\
\hline Canadá & $\nabla$ & $\nabla$ & $\Delta$ & $\nabla$ & $\Delta$ & $\Delta$ & $\nabla$ & $\nabla$ & $\nabla$ & $\nabla$ & $\Delta$ & $\nabla$ \\
\hline China & $\nabla$ & $\nabla$ & $\Delta$ & $\Delta$ & $\boldsymbol{\Delta}$ & $\nabla$ & $\boldsymbol{\Delta}$ & $\Delta$ & $\Delta$ & $\Delta$ & $\Delta$ & $\boldsymbol{\Delta}$ \\
\hline $\begin{array}{l}\text { Coreia do } \\
\text { Sul }\end{array}$ & $\Delta$ & $\nabla$ & $\boldsymbol{\Delta}$ & $\boldsymbol{\Delta}$ & $\nabla$ & $\nabla$ & $\nabla$ & $\Delta$ & $\nabla$ & $\nabla$ & $\Delta$ & $\boldsymbol{\Delta}$ \\
\hline $\begin{array}{l}\text { Estados } \\
\text { Unidos }\end{array}$ & $\Delta$ & $\boldsymbol{\Delta}$ & $\Delta$ & $\nabla$ & $\boldsymbol{\Delta}$ & $\boldsymbol{\Delta}$ & $\Delta$ & $\nabla$ & $\nabla$ & $\nabla$ & $\Delta$ & $\nabla$ \\
\hline França & $\Delta$ & $\Delta$ & $\Delta$ & $\Delta$ & $\Delta$ & $\Delta$ & $\Delta$ & $\nabla$ & $\Delta$ & $\nabla$ & $\Delta$ & $\Delta$ \\
\hline Índia & $\Delta$ & $\nabla$ & $\Delta$ & $\Delta$ & $\Delta$ & $\nabla$ & $\Delta$ & $\Delta$ & $\nabla$ & $\Delta$ & $\Delta$ & $\Delta$ \\
\hline Indonésia & $\Delta$ & $\nabla$ & $\nabla$ & $\Delta$ & $\nabla$ & $\nabla$ & - & - & $\Delta$ & $\Delta$ & $\Delta$ & $\Delta$ \\
\hline Irã & $\Delta$ & $\nabla$ & $\Delta$ & $\Delta$ & $\Delta$ & $\Delta$ & - & - & $\nabla$ & $\nabla$ & $\Delta$ & $\Delta$ \\
\hline Itália & $\Delta$ & $\Delta$ & $\Delta$ & $\Delta$ & $\Delta$ & $\Delta$ & - & - & $\Delta$ & $\nabla$ & $\Delta$ & $\Delta$ \\
\hline Japão & $\Delta$ & $\Delta$ & $\Delta$ & $\Delta$ & $\nabla$ & $\Delta$ & $\Delta$ & $\Delta$ & $\nabla$ & $\nabla$ & $\boldsymbol{\Delta}$ & $\nabla$ \\
\hline México & $\Delta$ & $\Delta$ & $\Delta$ & $\Delta$ & $\nabla$ & $\nabla$ & $\Delta$ & $\Delta$ & $\nabla$ & $\nabla$ & $\Delta$ & $\nabla$ \\
\hline $\begin{array}{l}\text { Reino } \\
\text { Unido }\end{array}$ & $\Delta$ & $\Delta$ & $\Delta$ & $\boldsymbol{\Delta}$ & $\boldsymbol{\Delta}$ & $\boldsymbol{\Delta}$ & $\nabla$ & $\nabla$ & $\nabla$ & $\nabla$ & $\boldsymbol{\Delta}$ & $\Delta$ \\
\hline Rússia & $\Delta$ & $\Delta$ & $\Delta$ & $\nabla$ & $\Delta$ & $\Delta$ & $\Delta$ & $\nabla$ & $\Delta$ & $\nabla$ & $\Delta$ & $\Delta$ \\
\hline Turquia & $\Delta$ & $\nabla$ & $\boldsymbol{\Delta}$ & $\boldsymbol{\Delta}$ & $\boldsymbol{\Delta}$ & $\nabla$ & - & - & $\nabla$ & $\Delta$ & $\Delta$ & $\Delta$ \\
\hline
\end{tabular}

Fonte: Elaborado pelos autores

Com relação às matrizes energéticas, nota-se que a grande maioria reduziu a participação do petróleo na matriz energética e aumentou a participação do gás natural e de outras fontes renováveis. Dos países 17 países que reduziram a participação no consumo em sua própria matriz energética, 9 deles aumentaram seu consumo relativo (quando comparado com o G20), ou seja, reduziram a participação em sua própria matriz mas aumentaram a participação no consumo do volume consumido no grupo (outros países passaram a consumir relativamente menos). Com o gás natural, o número foi mais expressivo: 19 países aumentaram a participação do consumo desta fonte em sua própria matriz energética. No caso do carvão, apenas 5 países aumentaram a participação desta fonte na própria matriz energética, comprometendo o desempenho do país. 
Com relação à energia nuclear, não houve consenso. Alguns países aumentaram a participação desta fonte em sua matriz energética (África do Sul, Brasil, China, Estados Unidos, França, Índia, Japão e México) enquanto outros países (Argentina, Canadá, Coreia do Sul e Reino Unido) reduziram a participação. Os demais países não fazem uso desta tecnologia como fonte energética.

O consumo de fonte de energia hidrelétrica na maioria dos países foi reduzido, indicando que a maioria dos países aumentou investimentos em outros recursos (como por exemplo, gás natural). Com relação aos outros recursos renováveis todos os países (com exceção da Arábia Saudita) aumentaram sua participação na própria matriz energética, contudo por ter participação relativamente pequena na composição da matriz, as alterações na eficiência dos países ainda são limitadas.

\subsubsection{Quadro consumo, absorção, emissões e desempenho DEA}

O Quadro 2resume a seguir apresenta os países que melhoraram $(\boldsymbol{\Delta})$, pioraram $(\boldsymbol{\nabla})$ ou mantiveram constante (-) seu consumo, absorção, emissões e desempenho e, também seu desempenho comparado aos demais países do G20.

Com relação ao consumo, apenas a Alemanha e a Rússia tiveram redução no consumo energético e, juntamente com a Itália e Reino Unido tiveram melhoras no desempenho temporal e em painel.

Com base neste quadro pode-se observar que apenas dois países (Alemanha e Rússia) reduziram o consumo energético, devido a alterações na matriz energética e aumento da área de floresta. No caso da Rússia, a redução no consumo energético pode estar ligada ao período que corresponde ao primeiro decênio analisado (1991-2000), em que o país acabara de ter sido desmembrado da antiga União Soviética (URSS) e estava em processo de reorganização política, econômica e produtiva. 
Quadro 2. Resumo do consumo, absorção, emissões e desempenho DEA

\begin{tabular}{|c|c|c|c|c|c|c|c|c|}
\hline \multirow{2}{*}{ País } & \multicolumn{2}{|c|}{ Consumo } & \multicolumn{2}{|c|}{ Absorção } & \multicolumn{2}{|c|}{ Emissões } & \multicolumn{2}{|c|}{ DEA } \\
\hline & Pais & $\mathrm{G} 20$ & Pais & $\mathrm{G} 20$ & Pais & $\mathrm{G} 20$ & Temporal & Painel \\
\hline África do Sul & $\nabla$ & $\boldsymbol{\Lambda}$ & - & $\Delta$ & $\boldsymbol{\nabla}$ & $\boldsymbol{\Delta}$ & - & $\nabla$ \\
\hline Alemanha & $\Delta$ & $\boldsymbol{\Lambda}$ & $\boldsymbol{\Delta}$ & $\Delta$ & $\Delta$ & $\boldsymbol{\Delta}$ & $\boldsymbol{\Delta}$ & $\boldsymbol{\Delta}$ \\
\hline Arábia Saudita & $\nabla$ & $\nabla$ & - & $\boldsymbol{\Lambda}$ & $\nabla$ & $\nabla$ & - & $\nabla$ \\
\hline Argentina & $\nabla$ & $\nabla$ & $\nabla$ & $\nabla$ & $\nabla$ & $\Delta$ & - & $\nabla$ \\
\hline Austrália & $\nabla$ & $\Delta$ & $\nabla$ & $\nabla$ & $\nabla$ & $\Delta$ & $\Delta$ & $\nabla$ \\
\hline Brasil & $\nabla$ & $\boldsymbol{\nabla}$ & $\nabla$ & $\nabla$ & $\boldsymbol{\nabla}$ & $\boldsymbol{\nabla}$ & $\nabla$ & $\nabla$ \\
\hline Canadá & $\boldsymbol{\nabla}$ & $\boldsymbol{\Lambda}$ & - & $\boldsymbol{\Delta}$ & $\boldsymbol{\nabla}$ & $\boldsymbol{\Lambda}$ & $\Delta$ & $\boldsymbol{\nabla}$ \\
\hline China & $\boldsymbol{\nabla}$ & $\nabla$ & $\boldsymbol{\Delta}$ & $\boldsymbol{\Lambda}$ & $\nabla$ & $\nabla$ & $\boldsymbol{\nabla}$ & $\nabla$ \\
\hline Coreia do Sul & $\nabla$ & $\nabla$ & $\nabla$ & $\nabla$ & $\boldsymbol{\nabla}$ & $\nabla$ & $\nabla$ & $\boldsymbol{\nabla}$ \\
\hline Estados Unidos & $\nabla$ & $\boldsymbol{\Delta}$ & $\boldsymbol{\Delta}$ & $\boldsymbol{\Delta}$ & $\nabla$ & $\Delta$ & $\Delta$ & $\nabla$ \\
\hline França & $\nabla$ & $\Delta$ & $\Delta$ & $\boldsymbol{\Lambda}$ & $\boldsymbol{\Lambda}$ & $\boldsymbol{\Delta}$ & $\Delta$ & $\nabla$ \\
\hline Índia & $\nabla$ & $\nabla$ & $\mathbf{A}$ & $\Delta$ & $\nabla$ & $\nabla$ & $\nabla$ & $\nabla$ \\
\hline Indonésia & $\boldsymbol{\nabla}$ & $\nabla$ & $\boldsymbol{\nabla}$ & $\nabla$ & $\boldsymbol{\nabla}$ & $\nabla$ & $\nabla$ & $\boldsymbol{\nabla}$ \\
\hline Irã & $\nabla$ & $\nabla$ & - & $\Delta$ & $\nabla$ & $\nabla$ & - & $\nabla$ \\
\hline Itália & $\nabla$ & $\Delta$ & $\boldsymbol{\Delta}$ & $\Delta$ & $\Delta$ & $\Delta$ & $\Delta$ & $\Delta$ \\
\hline Japão & $\nabla$ & $\Delta$ & $\Delta$ & $\Delta$ & $\nabla$ & $\Delta$ & $\Delta$ & $\nabla$ \\
\hline México & $\nabla$ & $\nabla$ & $\nabla$ & $\nabla$ & $\nabla$ & $\Delta$ & $\Delta$ & $\boldsymbol{\nabla}$ \\
\hline Reino Unido & $\boldsymbol{\nabla}$ & $\Delta$ & $\boldsymbol{\Delta}$ & $\boldsymbol{\Lambda}$ & $\Delta$ & $\Delta$ & $\boldsymbol{\Lambda}$ & $\boldsymbol{\Delta}$ \\
\hline Rússia & $\Delta$ & $\Lambda$ & $\Delta$ & $\boldsymbol{\Lambda}$ & $\Delta$ & $\Delta$ & $\Delta$ & $\boldsymbol{\Delta}$ \\
\hline Turquia & $\nabla$ & $\boldsymbol{\nabla}$ & $\boldsymbol{\Delta}$ & $\boldsymbol{\Delta}$ & $\boldsymbol{\nabla}$ & $\nabla$ & - & $\nabla$ \\
\hline
\end{tabular}

Fonte: Elaborado pelos autores

Com relação às mudanças no uso da terra houve redução da área total de floresta no grupo analisado. Assim, os países que aumentaram (ou mantiveram inalterada) sua área de floresta, melhoraram o desempenho em relação ao G20. Outra observação quanto às mudanças no uso da terra é que nenhum país com redução na área de floresta melhorou seu desempenho ao longo do tempo.

As características dos grupos analisados, incluindo as justificativas de seus desempenhos são apresentadas no Quadro3.

Quadro 3. Resumo da eficiência dos países 


\begin{tabular}{|c|c|c|}
\hline Categoria & Paises & $\begin{array}{l}\text { Caracteristicas } \\
\end{array}$ \\
\hline Sempre eficientes & $\begin{array}{c}\text { Africa do Sul } \\
\text { Arábia Saudita } \\
\text { Turquia } \\
\text { Argentina }\end{array}$ & $\begin{array}{l}\text { São paises com baixo consumo em } 1990\left(15^{2}, 16^{2}, 19^{2} \text { e } 20^{2} \text { posição }\right. \\
\text { respectivamente) e baixas emissões }\left(14^{2}, 18^{2}, 20^{2} \text { e } 19 \text { posição respectivamente). }\right. \\
\text { Todos os paises deste grupo aumentaram a participação de gás natural e outros } \\
\text { recursos renováveis na matriz e em maior intensidade que o grupo (consumo } \\
\text { relativo), com exceção da Arábia Saudita que não faz uso de carvão e outros } \\
\text { recursos renováveis. Todos os paises deste grupo reduziram o consumo do carvão, } \\
\text { sendo que apenas a Turquia não melhorou o consumo em relaçẫo ao } \mathrm{G} 20 \text {. }\end{array}$ \\
\hline $\begin{array}{c}\text { Paises que se tornaram } \\
\text { eficientes }\end{array}$ & $\begin{array}{l}\text { Austrália } \\
\text { Irã }\end{array}$ & $\begin{array}{l}\text { Os paises deste grupo aumentaram em sua matriz energética o consumo de } \\
\text { combustiveis menos poluentes (gás natural e outros renováveis), além de reduzir o } \\
\text { consumo de petróleo. Quanto ao carvão, apenas o Irã reduziu o consumo em sua } \\
\text { matriz energética, mas os dois paises tiveram redução no consumo relativo ao } \\
\text { G20. Apesar do uso na Austrália, carvão utilizado no país é de alta qualidade } \\
\text { (maior poder calorifico com menor emissão de GEE) }\end{array}$ \\
\hline $\begin{array}{c}\text { Paises ineficientes com } \\
\text { melhora na eficiência na } \\
\text { análise temporal e na análise } \\
\text { com dados em painel }\end{array}$ & $\begin{array}{l}\text { Alemanha } \\
\text { Itália } \\
\text { Reino Unido } \\
\text { Rússia }\end{array}$ & $\begin{array}{l}\text { Os paises deste grupo, que melhorou eficiència temporal e com dados em painel, } \\
\text { teve como caracteristicas a redução no consumo de fontes mais poluentes (carvão } \\
\text { e petróleo) em sua matriz energettica e aumento no consumo de fontes menos } \\
\text { poluentes (gás natural e outros renováveis). Dentre estes paises apenas o Reino } \\
\text { Unido não melhorou o consumo de energia hidrelétrica (menos poluente). Como } \\
\text { diferencial, este grupo tambèm reduziu o consumo relativo ao } \mathrm{G} 20 \text { (sendo que a } \\
\text { Alemanha e Rússia reduziram seu consumo energético) e aumentaram a àrea de } \\
\text { floresta (mudança no uso da terra) e absorção. Desta forma, nestes paises houve } \\
\text { redução nas emissões quando comparadas à } 1990 \text {. }\end{array}$ \\
\hline $\begin{array}{l}\text { Paises ineficientes com } \\
\text { melhora apenas na } \\
\text { eficiência temporal }\end{array}$ & $\begin{array}{l}\text { França } \\
\text { Canadá, } \\
\text { Estados Unidos } \\
\text { Japão } \\
\text { México }\end{array}$ & $\begin{array}{l}\text { Este grupo apresenta algumas caracteristicas comuns, dentre elas o aumento no } \\
\text { consumo de gás natural e de recursos renováveis em sua matriz energética (fatores } \\
\text { positivos) e o aumento consumo energético de cada pais (fator negativo). Em todos } \\
\text { os paises a participação do consumo relativo de energia hidrelétrica piorou em } \\
\text { relação ao grupo. Com exceção do México, nos demais paises deste grupo o } \\
\text { aumento do consumo de carvão foi menor que o aumento médio do grupo, fazendo } \\
\text { com que o consumo relativo de carvão nestes paises fosse reduzido. }\end{array}$ \\
\hline $\begin{array}{l}\text { Paises que se tornaram } \\
\text { ineficientes }\end{array}$ & $\begin{array}{l}\text { Brasil } \\
\text { Coreia do Sul } \\
\text { Indonésia }\end{array}$ & $\begin{array}{l}\text { Em } 1990 \text { os paises deste grupo tiveram score de eficiência de } 100 \% \text { por razões } \\
\text { diferenciadas. A Indonésia tinha baixo consumo relativo (ocupando a } 18^{2} \text { posição } \\
\text { no consumo do } \mathrm{G} 20 \text { ), a Coreia do Sul tinha baixa dependência de combustiveis } \\
\text { fosseis (sendo que o pais era o } 16^{2} \text { maior dependente dentre os } 20 \text { paises) e o Brasil } \\
\text { era o pais com menor dependência de combustiveis fósseis e com a maior } \\
\text { participação em recursos renováveis (hidrelétricas e outras fontes renováveis). } \\
\text { As razões para que eles paises perdessem eficiência ao longo do tempo foram o } \\
\text { aumento no consumo energético, superior à média do } \mathrm{G} 20 \text {, e a redução da área de } \\
\text { floresta. Em todos os paises houve aumento de outros recursos renováveis em sua } \\
\text { matriz energética (com pequena participação na matriz) e redução do consumo de } \\
\text { petróleo. O Brasil tornou-se o } 8^{\circ} \text { pais com maior consumo energético e o } 6^{\circ} \mathrm{em} \\
\text { emissões de } \mathrm{GEE} \text {, a Coreia do Sul aumentou a dependência de combustiveis } \\
\text { fósseis e passou a ser o } 9^{\circ} \text { pais em consumo e o } 11^{\circ} \text { em emissões e a Indonésia foi } \\
\text { o pais que mais reduziv a àrea de floresta. }\end{array}$ \\
\hline $\begin{array}{l}\text { Paises ineficientes com } \\
\text { queda na eficiência }\end{array}$ & China e Índia & $\begin{array}{l}\text { A China e India, os dois paises mais populosos do mundo, tinham grandes } \\
\text { emissões de GEE em } 1990\left(2^{2} \text { e } 4^{2} \text { maiores emissões respectivamente). Com alto }\right. \\
\text { consumo energético no ano base, os paises ainda aumentaram o consumo de } \\
\text { maneira mais acentuada que outros paises do } \mathrm{G} 20 \text {. O aumento no consumo de gás } \\
\text { natural, outros recursos renováveis, energia nuclear e também aumento na area de } \\
\text { floresta não foram suficientes para evitar queda na eficiência. Outra caracteristica } \\
\text { é que, ainda que os paises tenham reduzido a participação do carvão em sua matriz } \\
\text { energética, em comparação ao G20 houve aumento relativo no consumo. }\end{array}$ \\
\hline
\end{tabular}

Fonte: Elaborado pelos autores

O consumo de combustíveis fósseis teve apenas alguns pontos congruentes para todos os países, como o aumento da participação do gás na matriz energética (com exceção da Indonésia). No caso dos Estados Unidos, além do aumento do consumo (em um país já com alto consumo em 1990) houve redução na participação de hidrelétricas e queda na participação do consumo relativo de gás natural do G20 (ambos menos poluentes). No caso da 
França, o consumo energético foi a principal causa para o desempenho do país que teve apenas uma pequena perda de desempenho na análise com dados em painel.

Dentre os países analisados, dois países que reduziram o consumo energético, sendo que a Rússia pode ter reduzido seu consumo, em parte, pela redução do crescimento na primeira década (1991-2000) enquanto a Alemanha teve crescimento econômico em todo período, com redução no consumo energético por alterações na matriz energética e mudanças no uso da terra. Os dois países, Alemanha e Rússia, melhoraram seu desempenho tanto na análise temporal quanto na análise com dados em painel devido às alterações nos próprios países.

Na Austrália, o diferencial foi que o país teve redução na participação do consumo de carvão em relação ao G20, além de reduzir a participação de petróleo e aumentar a participação de gás natural em sua matriz energética. Enquanto no México, reduziu-se o consumo relativo de petróleo e aumentou-se o consumo de gás natural e energia nuclear.

\subsubsection{Variações nos scores de eficiência entre 1990 e 2010}

Como forma de comparação dos dados referentes à análise temporal e com dados em painel, foi calculada a variação entre os scores entre 1990 (ano base) e 2010 (última medição) dos dois modelos (Tabela 6).

Tabela 6.Variação nos scores entre 1990 e 2010 (nos modelos com e sem $\mathrm{C}_{\text {mut }}$ )

\begin{tabular}{lcccc}
\hline \multicolumn{1}{c}{ Países } & \multicolumn{2}{c}{ Variação 1990-2010 (com C mut } & \multicolumn{2}{c}{ Variação 1990-2010 (sem C } \\
& $\Delta \%$ Tempor & \\
& $0,0 \%$ & $\Delta \%$ Painel & $\Delta \%$ Temporal & $\Delta \%$ Painel \\
\hline África do Sul & $298,3 \%$ & $-34,1 \%$ & $0,0 \%$ & $-34,1 \%$ \\
Alemanha & $0,0 \%$ & $48,3 \%$ & $286,9 \%$ & $47,5 \%$ \\
Arábia Saudita & $0,0 \%$ & $-50,4 \%$ & $0,0 \%$ & $-50,4 \%$ \\
Argentina & $79,2 \%$ & $-26,5 \%$ & $0,0 \%$ & $-25,0 \%$ \\
Austrália & $-42,7 \%$ & $-19,2 \%$ & $97,6 \%$ & $-17,8 \%$ \\
Brasil & $46,8 \%$ & $-84,1 \%$ & $-16,2 \%$ & $-76,6 \%$ \\
Canadá & $-95,5 \%$ & $-46,3 \%$ & $74,8 \%$ & $-34,6 \%$ \\
China & $-45,5 \%$ & $-99,1 \%$ & $-94,5 \%$ & $-99,1 \%$ \\
Coreia do Sul & $100,0 \%$ & $-81,3 \%$ & $-45,2 \%$ & $-81,3 \%$ \\
Estados Unidos & $200,0 \%$ & $-50,0 \%$ & $100,0 \%$ & $-50,0 \%$ \\
França & $-54,5 \%$ & $-2,9 \%$ & $199,4 \%$ & $-1,1 \%$ \\
Índia & $-25,7 \%$ & $-87,3 \%$ & $-52,3 \%$ & $-87,2 \%$ \\
Indonésia & $0,0 \%$ & $-65,5 \%$ & $-17,0 \%$ & $-62,8 \%$ \\
Irã & $127,7 \%$ & $-61,1 \%$ & $0,0 \%$ & $-61,1 \%$ \\
Itália & $122,9 \%$ & $7,6 \%$ & $123,9 \%$ & $7,2 \%$ \\
Japão & & $-22,9 \%$ & $122,2 \%$ & $-22,2 \%$
\end{tabular}

REAd - Porto Alegre - Edição 86 - No 2 - Maio / Agosto 2017 - p. 306 - 332 


\begin{tabular}{lcccc} 
México & $0,8 \%$ & $-63,5 \%$ & $6,2 \%$ & $-60,0 \%$ \\
Reino Unido & $395,3 \%$ & $57,4 \%$ & $391,3 \%$ & $57,0 \%$ \\
Rússia & $794,7 \%$ & $31,6 \%$ & $664,3 \%$ & $14,3 \%$ \\
Turquia & $0,0 \%$ & $-43,1 \%$ & $0,0 \%$ & $-42,6 \%$ \\
\hline
\end{tabular}

Fonte: Elaborado pelos autores (2014), com base nos relatórios do software DEA Frontier

Nota-se que há a formação de grupos em função do desempenho, com segmentação próxima à que foi apresentada neste trabalho. Há o grupo dos países com melhora no desempenho, tanto quando comparado a outros países quanto quando comparado ao seu próprio desempenho ao longo do tempo, representado pelos países Rússia, Reino Unido, Alemanha e Itália. A França se aproxima do grupo, com tendência de melhora de desempenho.

Os grupos dos países que mantiveram seu desempenho em 100\% (sem variação na análise temporal), perderam eficiência ao longo do tempo. Há ainda o grupo de países que melhorou seu desempenho em relação aos outros países do grupo, mas com queda da eficiência ao longo do tempo (Estados Unidos, Canadá, Japão e México). Por fim, observa-se no terceiro um grupo com baixo desempenho, com países que perderam desempenho quando comparado a outros países e perderam eficiência ao longo do tempo.

Para serem comparados os países, segundo o modelo que considera apenas as emissões de GEE no output,as variações no score temporal foram plotadas em um eixo $\mathrm{X}$ enquanto as variações no score com dados em painel foram plotadas em um eixoY. Pode-se observar que os países ocupam praticamente as mesmas posições, com pequenas alterações entre os países Brasil e Coreia do Sul, Canadá e Turquia e Irã e México.

Desta comparação, decorre-se que a inserção do coeficiente de mudança no uso da terra não altera substancialmente o desempenho dos países (uma vez que as emissões relativas de GEE pelas florestas são pequenas quando comparadas a outras fontes de carbono), contudo é preponderante para melhorar o desempenho do país ao longo do tempo.

Destaque interessante encontrado na análise aponta que todos os países que aumentaram a participação relativa no consumo de carvão ou de petróleo pioraram o desempenho ao longo do tempo (análise com dados em painel), sendo que os países que aumentaram a participação relativa no consumo de ambas as fontes também pioraram o desempenho em relação aos demais países (análise temporal).

Dos que melhoraram seu desempenho na análise temporal (Alemanha, Estados Unidos, França, Itália, Japão, Reino Unido e Rússia) apenas os Estados Unidos, França e Japão não melhoraram seu desempenho em relação ao próprio desempenho em 1990 (análise com dados em painel). Nestes três países o aumento do consumo energético foi um dos fatores 
responsáveis pelo desempenho inferior, sendo que no Japão, além do aumento do consumo energético também houve aumento da participação do carvão em sua matriz energética.

Os países que pioraram seu desempenho (China e Índia) alteraram sua matriz energética para o consumo de fontes menos poluentes (aumento do consumo do gás natural, fontes renováveis e energia nuclear além da redução do uso do carvão) e aumentaram a área de floresta. O baixo desempenho, no entanto, é resultado do alto consumo energético (desde 1990) e da participação dos países no consumo de combustíveis fósseis poluentes no grupo (aumento no consumo relativo de carvão e petróleo).

Os países que aumentaram o consumo energético, de maneira mais acentuada que os demais países do G20, pioraram seu desempenho em relação ao próprio desempenho de 1990 (análise com dados em painel) e, na maioria dos casos, pioraram seu desempenho em relação aos demais países do grupo (análise temporal). Alguns países, no entanto, que também aumentaram o consumo energético, conseguiram melhoraram seu desempenho em relação a outros países do grupo (análise temporal). Nestes países, o aumento do consumo foi compensado pelas alterações positivas em quase todos os outros indicadores da matriz energética (redução do petróleo e carvão e aumento no consumo de fontes renováveis).

\section{CONSIDERAÇÕES FINAIS}

A maioria dos países reduziu o consumo de petróleo e de carvão alterando, assim, as características das emissões de GEE. Alguns deles, no entanto, priorizaram seus recursos em fontes mais poluentes, como o caso da África do Sul, Canadá e China (que aumentaram o consumo de petróleo), da Indonésia (que reduziu o consumo de gás natural em sua matriz energética) e a Austrália, Coreia do Sul, Indonésia, Japão e México (que aumentaram o consumo de carvão em seus países).

Em relação ao gás natural, não houve consenso, pois, alguns países que reduziram a participação no consumo de gás natural tiveram melhores desempenhos em função da combinação de outros fatores (petróleo, carvão, consumo e alterações na área de floresta).

Dentre os que aumentaram a participação da energia nuclear em sua matriz energética, apenas três países pioraram seu desempenho, sendo que dois deles (China e Índia, os dois países mais populosos do mundo e com maior participação no consumo e emissões) tiveram seu desempenho reduzido devido ao aumento de consumo ao longo do tempo.Já o terceiro país, o Brasil, teve seu desempenho comprometido pelo desmatamento. 
Em relação às hidrelétricas e outras fontes renováveis também não se pode tirar conclusões precisas, uma vez que as alterações no uso de hidrelétricas geraram resultados diversos no desempenho dos países, devido à combinação de outros fatores (outras fontes, consumo e mudanças no uso da terra).No caso de outras fontes renováveis, não se pode inferir relação devido ao fato de que todos os países aumentaram a participação do consumo destas fontes em sua matriz energética.

A questão referente às mudanças no uso da terra, todos os países que reduziram a área de floresta (Argentina, Austrália, Brasil, Coreia do Sul, Indonésia e México) tiveram perda de eficiência na análise de desempenho com dados em painel, indicando que tinham desempenho melhor no ano base (1990). Dentre os que reduziram a área de floresta, apenas a Austrália e o México melhoraram seu desempenho na análise temporal. E, dentre os países que pioraram seu desempenho, a Coreia do Sul e a Indonésia aumentaram o consumo de carvão em sua matriz energética.Já o Brasil, juntamente com a Coreia do Sul, reduziu sua participação no consumo de hidrelétricas.

Nos países onde não houve mudança no uso da terra, também não houve aumento de eficiência com dados em painel, sugerindo que o aumento na área de floresta pode ser um fator importante para que o país melhore seu desempenho em relação à sua posição no ano base.

Assim, as alterações na matriz energética, em especial na redução do consumo de combustíveis fósseis carvão e petróleo ou na substituição destas fontes por gás natural (combustível fóssil menos poluente) permitem melhores desempenhos na emissão de GEE, em especial quando comparado a outros países (análise temporal). As alterações na matriz energética das outras fontes (energia nuclear, hidrelétrica e outras fontes renováveis) permitem ganhos de eficiência em caso de alterações combinadas na matriz dos países.

As mudanças no uso da terra, ainda que não alterem de maneira substancial o desempenho comparado dos países, permite que os países melhorem o desempenho ao longo do tempo (análise com dados em painel). Isto significa que, caso um país queira melhorar seu desempenho em relação à um ano base (como proposto pela ONU), é necessário que o país direcione seus esforços para o florestamento ou reflorestamento.

Da mesma forma, países que reduziram sua área de floresta (desmatamento) pioraram seu desempenho ao longo do tempo, potencializando as emissões de GEE, tanto pelas queimadas e liberação direta de $\mathrm{CO} 2$ no meio ambiente quanto pela redução de sequestro e absorção pelo meio ambiente. 
Com relação ao consumo, alguns países reduziram o consumo energético mesmo com crescimento econômico, sugerindo que é possível manter crescimento econômico com redução no consumo energético. Um dos fatores que explicam esta alteração está no uso de tecnologias mais recentes que permitem reduzir as emissões de GEE. Com tecnologias mais novas os países tendem a emitir menos poluentes ao meio ambiente no processo de geração de energia. Países mais desenvolvidos têm alterado seu processo de produção neste sentido enquanto países em desenvolvimento o fazem mais tardiamente.

Por fim, o uso de tecnologias mais limpas (baseadas em energia eólica, solar, movimento das marés e outras fontes) pode permitir importante redução nas emissões, mas conforme discutido neste trabalho, com um custo altíssimo e dependente de fortes investimentos e incentivos dos governos.

Nesse contexto, considera-se que o aquecimento global antropogênico é um fato inegável, com possíveis consequências desastrosas para os países e passível de ser parcialmente corrigido. Para isto é preciso uma maior conscientização dos países para que as decisões sejam tomadas em benefício comum (internacional) ao invés de benefícios particulares (domésticos), o que inclui maior envolvimento e participação dos governos nas negociações ambientais e no financiamento de projetos mais limpos.

\section{REFERÊNCIAS}

ABEN -Associação Brasileira de Energia Nuclear.Análise comparativa das alternativas energéticas quanto às emissões diretas e indiretas de $\mathbf{C O}_{2}$. 2008. Disponível em: <http://www.zonaeletrica.com.br/downloads/20080410_ibama_3.pdf>.Acessoem: 14 ago. 2012.

AVKIRAN, N.; PARKER, B.Pushing the DEA research envelope. Socio-Economic Planning Sciences, Amsterdam, n.44, p. 1-7, 2010.

BACCINI, A. et al.Estimated carbon dioxide emissions from tropical deforestation improved by carbon-density maps. Nature Climate Change, [s.1.],v.2, 2012.

BANKER, R. D.; CHARNES, A.; COOPER, W. W. Some Models for Estimating Technical and Scale Inefficiencies in Data Envelopment Analysis. Management Science, Catonsville, v. 30, n. 9, 1984.

BIAN, Y.; HE, P.; XU, H. Estimation of potential energy saving and carbon dioxide emission reduction in China based on an extended non-radial DEA approach. Energy Policy, Amsterdam, v. 63, p. 962-971, 2013.

BP - Statistical Review of World Energy. 2013. Disponível em: $<$ http://www.bp.com/content/dam/bp/pdf/statisticalreview/statistical_review_of_world_energy_2013.pdf>. Acesso em: 09 nov. 2014 
BRONZATTI, F. L.; IAROZINSKI NETO, A. Matrizes energéticas no Brasil: Cenário 2010-2030. ENCONTRO NACIONAL DE ENGENHARIA DE PRODUÇÃO, 28., Rio de Janeiro, 2008. Rio de Janeiro, RJ: ENEP, 2008.p. 13-16.

CAMMACK, P. The G20, the Crisis, and the Rise of Global Developmental Liberalism. Third World Quarterly, Abingdon, v. 1, n. 33, p. 1-16, 2012.

COOPER, W.; SEIFORD, L.; TONE, K., Data Envelopment Analysis: A Comprehensive Text with Models, Applications, References and DEA-Solver Software. Boston: KluwerAcademicPublishers, 2007.

CORADESQUI, S.; SANTOS, P. R. D. Análise de viabilidade econômica da produção de shalegas: um estudo de caso em Fayetteville. Escola Politécnica, Universidade Federal do Rio de Janeiro (UFRJ), 2013

ENERGY INFORMATION ADMINISTRATION - EIA. Levelized Cost of New Generation Resources in the Annual Energy Outlook 2013. Report of the US Energy Information Administration of the U.S. Department of Energy (DOE), 2013.

GARMAN, C.; JOHNSON, R. Petróleo: O Brasil no contexto de um panorama global em transformação. In: GIAMBIAGI, F.; LUCAS, L. P. Petróleo: Reforma e contrarreforma do setor petrolífero brasileiro. Fabio Giambiagi e Luiz Paulo Vellozo Lucas (org.), Rio de Janeiro: Elsevier, 2013

GOLDEMBERG, J.; LUCON, O. Energia, meio ambiente e desenvolvimento. São Paulo: Editora da USP, 2008.

GRID ARENDAL. Carbon management in natural ecosystems.Centre collaborating with the United Nations Environment Programme (UNEP), 2013

HINRICHS, R.; KLEINBACH, M.; REIS, L. B. Energia e Meio Ambiente. 4.Ed. São Paulo: Cengage Learning, 2012.

HÖHNE, N. et al.The rules for land use, land use change and forestry under the Kyoto Protocol - lessons learned for the future climate negotiations. Environmental Science \& Policy, Amsterdam, v. 10, n. 4, p. 353-369, 2007.

HUBER, J. Pioneer countries and the global diffusion of environmental innovations: Theses from the viewpoint of ecological modernisation theory. Global Environmental Change, Amsterdam, v. 18, n. 3, p. 360-367, 2008.

INTERNATIONAL ATOMIC ENERGY AGENCY - AIEA. Nuclear Power Reactors in the World, United Nations, 2012

ISHIGURO, Y. A energia nuclear para o Brasil. São Paulo: Makron Books, 2002

KAHLER, M. Rising powers and global governance: negotiating change in a resilient status quo. InternationalAffairs, Hoboken, v. 89, n. 3, p. 711-729, 2013. 
LEITE, A. D. Eficiência e desperdício da energia no Brasil. Rio de Janeiro: Elsevier, 2013.

MCLEAN, E. V.; STONE, R. W. The Kyoto Protocol: Two-Level Bargaining and European Integration1. InternationalStudiesQuarterly, Hoboken, v. 56, n. 1, p. 99-113, 2012.

PEDRO, L. A. Carbono do solo e mitigação da mudança climática global. Química Nova, São Paulo, v.28, n.2, p. 329-334, 2005.

PINTO JUNIOR; H. Q. et al. Economia da Energia: fundamentos econômicos, evolução histórica e organização industrial. Helder Queiroz Pinto Junior. Rio de Janeiro: Elsevier, 2007.

PORTIER, C. J.et al. A human health perspective on climate change: a report outlining the research needs on the human health effects of climate change. Journal of Current Issues in Globalization, [s.1.], v. 6, n. 4, p. 621-710, 2013.

RAMOS, L. Potências médias emergentes e reforma da arquitetura financeira mundial? Uma análise do BRICS no G20. Revistade SociologiaPolítica, Curitiba, v. 22, n. 50, p. 49-65, 2014.

ROSA, A. H.; FRACETO, L. F; MOSCHINI-CARLOS, V. Meio Ambiente e

Sustentabilidade.Porto Alegre: Bookman, 2012

SALGADO JUNIOR, A. P. et al.Investment potential for new sugarcane plants in Brazil based on assessment of operational efficiency. International Food and Agribusiness Management Review,Minneapolis, v. 17, n. 2, p. 41-64, 2014.

SALGADO JUNIOR, A. P.; NOVI, J. C. Administrative and pedagogical practices that can contribute to the performance of students in municipal elementary schools in ProvaBrasil.

Ensaio: Avaliação e Políticas Públicas em Educação, Rio de Janeiro, v. 23, n. 88, p. 631$662,2015$.

SARAFIDIS, V. An Assessment of Comparative Efficiency Measurement

Techniques.London: EuropeanEconomics, 2002. Disponível em: <http://www.europeeconomics.com/download/eeeff.pdf>. Acesso em: 20 nov. 2015

SEIFFERT, M. E. B. Mercado de Carbono e Protocolo de Quioto: Oportunidades de negócio na busca da sustentabilidade. 2. ed. São Paulo: Atlas, 2013.

SPADARO, J.; LANGLOIS, L.; HAMILTON, B. Assessing the Difference: Greenhouse Gas Emissions of Electricity Generating Chains.IAEA Bulletin, Vienna, v. 42, n. 2, 2000.

VIANA, A. R.; CINTRA, M. A. M. G20: os desafios da coordenação Global e da rerregulação financeira. Boletim de Economia e Política Internacional, IPEA, [s.l.], n. 1, 2010.

WORLD BANK. World Bank Open Data. 2013. Disponível em:

<http://data.worldbank.org/>. Acesso em: 10 nov. 2015 